\title{
Who gets fully-paid maternity leave? population-based survey of postpartum women, oregon, 2010
}

\author{
Jena L Fellenzer ${ }^{1}$, Kenneth D Rosenberg ${ }^{2 *}$, Danielle J Lindemann ${ }^{3}$, Linda Houser ${ }^{4}$, Alfredo P Sandoval ${ }^{1}$ and Kathryn L Broderick ${ }^{1}$ \\ ${ }^{1}$ Oregon Public Health Division, Portland, USA \\ ${ }^{2}$ Oregon Health \& Science University - Portland State University School of Public Health, Portland, USA \\ ${ }^{3}$ Lehigh University, Bethlehem, PA, USA \\ ${ }^{4}$ Widener University, Chester, PA, USA
}

\begin{abstract}
Objective: Previous scholarship has demonstrated that maternity leave is associated with good overall physical and mental health of the mother and child. However, taking time off to recover from a birth and bond with a new child challenges families' economic security when such leave is not fully-paid. We examine a populationbased sample of Oregon women to identify factors associated with access to fully-paid leave versus partially-paid leave, unpaid leave, and no leave.

Methods: We used a state population-based survey of postpartum women who had a 2008 live birth to explore differences in access to fully-paid maternity leave. The Oregon Pregnancy Risk Assessment Monitoring System (PRAMS) asks a stratified random sample of Oregon women about their experiences before, during, and after pregnancy; Oregon PRAMS-2 is a follow-back survey conducted when the child reaches 2 years of age. We used weighted multivariate regression to explore the association between annual household income and self-reported fully-paid maternity leave.

Results: Among women who had been working during the last three months of pregnancy, 16.1\% reported having been offered fully-paid, $16.3 \%$ partially-paid and $49.8 \%$ unpaid maternity leave; $17.7 \%$ were offered no maternity leave. In multivariate analysis, high-income women ( $\geq 300 \%$ Federal Poverty Level) were more likely to have been offered fully-paid maternity leave than low-income women (ORa 3.57,95\% confidence interval 1.24-10.3).

Conclusions: Few women receive fully-paid maternity leave. Policies ensuring fully-paid maternity leave will be particularly beneficial to lower-income women. A national paid leave policy would improve postpartum life for women and infants.
\end{abstract}

\section{Introduction}

Previous research has called attention to the benefits of maternity leave for working women and their families. Time off from the workplace facilitates the mother's recovery from childbirth and fosters maternal-infant attachment [1]. Mothers with access to time off after birth are more likely to breastfeed, bond with their infants, seek wellchild care, and complete immunizations; they also detect potential developmental delays sooner than mothers without time off $[2,3]$. The benefits of postpartum leave also include fewer maternal mental health symptoms [4]. For example, one study found that a maternity leave that is 6 weeks or less was associated with less maternal positive affect and responsiveness to infant cues relative to the same characteristics recorded for mothers with longer leaves [5].

Previous studies have detailed the numerous benefits of paid maternity leave, in particular. For instance, paid leave may reduce infant and child morbidity and mortality [6]. Paid maternity leave also improves the odds of women taking leave and returning to their employers. Research shows that women who live in states that have some kind of paid leave program are twice as likely to take paid leave following the birth of a child as are women in states without these policies $[7,8]$. Other scholarship has supported this connection between legislative action and leave-taking behavior; Waldfogel [9], for instance, found that leave usage increased after the implementation of the Family and Medical Leave Act of 1993.
Studies show that those with paid leave also tend to have higher rates of return to work and an increase in working hours relative to those who use only unpaid leave [10,11]. Furthermore, Houser and Vartanian [12] found that women who return to work after paid leave have "stronger labor force attachment and positive changes in wages" (p. 3). Boushey [13] found that, women with paid maternity leave had higher post-birth wages than other mothers.

One study found that mothers facing financial strain were more likely to return to work within twelve weeks as those who experienced no financial strain [14]. These studies suggest greater employee retention for women with low incomes, fewer turnovers, and lower replacement costs with the implementation of paid leave policies. Paid leave increases the likelihood of a mother taking time off to achieve her desired work/life balance, and it raises economic security among families. Without paid maternity leave, many women struggle to afford time off to take care of themselves and their newborns after the birth of a new child.

*Correspondence to: Kenneth D Rosenberg, Oregon Public Health Division, 800 NE Oregon Street, Suite 825, Portland, OR 97232, USA, Tel: 971-673-0237; Fax: 971-673-0231; E-mail: ken.d.rosenberg@state.or.us

Key words: maternity leave, paid leave, prams, oregon, pregnancy, infant

Received: April 30, 2018; Accepted: May 18, 2018; Published: May 22, 2018 
Yet access to maternity leave varies widely. Most employed women in the United States do not have access to paid maternity leave; only half of all first-time mothers take paid leave in connection with childbirth [15]. Maternity leave policies differ from state to state and company to company. Many U.S. workers are covered by the Family and Medical Leave Act (FMLA) of 1993, which provides 12 weeks of job-protected leave for pregnancy, childbirth adoption and illness. However, $41 \%$ of workers, and an even higher proportion of low-wage workers, are not eligible for FMLA [16], which only applies to employees who have worked for the same employer for at least 1,250 hours over a minimum of 12 months in a company with 50 or more employees. Further, while FMLA protects employees' jobs, it does not guarantee them pay. The benefits of the FMLA are not within the reach of mothers who cannot afford to take unpaid time off from work. To minimize the loss of income during maternity leave, expectant mothers often accumulate general leave time before childbirth and forgo vacation and sick days. In the absence of public paid leave policies, many women are forced to choose between taking time off to recover from childbirth and bond with their new child and financial security.

Access to leave and leave-taking behavior have been shown to vary by maternal characteristics. For example, prior work has indicated an association between income and access to leave [1,17-20]. The Institute for Women's Policy Research found that well-paid people who work in managerial or professional occupations at companies with 100 employees or more are the most likely to have the benefit of paid leave [21]. Other work supports this point that higher-income workers are also more likely to have access to paid leave, while low-income families disproportionately carry the economic hardship associated with the lack of paid maternity leave policies [22,23]. Studies by Ross Phillips [18] and Laughlin [15] found that women who were married and women with bachelor's degrees or higher levels of education were more likely to have access to paid maternity leave. A more recent study by Shepherd-Banigan \& Bell [23], using multivariate models controlling for other socio-demographic characteristics, found that mothers who were privately insured, working full-time (versus part-time), and from higher income families were more likely to receive paid maternity leave.

Leave-taking behavior also varies by race: the Centers for Disease Control and Prevention (CDC) Survey of Family Growth found that Hispanic women were less likely to report having taken maternity leave compared with non-Hispanic White and Black women [17]. In their sample of postpartum women, Shepherd-Banigan \& Bell [23] found that non-Hispanic Black women were significantly more likely than non-Hispanic White women to receive paid maternity leave, at higher levels and for longer periods of time [24].

Despite the wealth of evidence suggesting that paid maternity leave has the potential to increase positive birth outcomes and promote maternal and child health, and research pointing to vast differences in rates of access, for the most part this previous scholarship does not delineate between fully-paid and partially-paid leave. To our knowledge, no studies have identified the maternal characteristics of women with access to fully-paid maternity leave, relative to other leave statuses, in a state population-based sample and using a well-established source of data on postpartum women.

This study was designed to address the gaps in the available literature through secondary analysis of a population-based sample from the state of Oregon. We explored the association between having fully-paid maternity leave and family income as well as additional covariates, such as race/ethnicity. For health care providers and public health professionals, more information about women who may not receive maternity leave is crucial in identifying those at greater risk for adverse maternal and infant consequences. This information can also inform the design and implementation of policies and programs intended to broaden access to paid maternity leave, such as state-wide or federal paid maternity leave legislation.

\section{Maternity Leave in Oregon}

As noted above, federal law (FMLA) provides 12 weeks of jobprotected leave for pregnancy, childbirth, adoption, and illness. Under the Oregon Family Leave Act (OFLA) passed by the 1995 Legislature, women may take up to 12 weeks of job-protected leave for maternity leave. Under both FMLA and OFLA, maternity leave is unpaid but women may use any accrued paid leave time (vacation, sick or compensative time) during leave in order to receive payment while out of work.

\section{Methods}

Data were obtained from three linked data sources: Oregon Pregnancy Risk Assessment Monitoring System (PRAMS) for 2008 births; the follow-back survey, Oregon PRAMS-2; and the birth certificates for the respondents' infants. PRAMS is a state-based system of surveys of postpartum women (2-6 months after a live birth) established by CDC and conducted by 40 state health departments and New York City. Women are selected by stratified random sampling from birth certificates every month, with oversampling of racial/ethnic minorities. Mothers receive a second survey, PRAMS-2, shortly after the index child's second birthday. Oregon PRAMS-2 was administered to all mothers who responded to the Oregon PRAMS survey, except those who indicated that they did not wish to be contacted again or whose babies were deceased. Oregon PRAMS-2 includes questions on maternal depression, stressful life events, and intimate partner violence occurring 13 to 24 months after birth, as well as questions regarding maternal marital status, maternal education, pregnancy intention, and maternal social support. Using its 2010 PRAMS-2 survey, Oregon became the first state to ask specifically about maternity leave. The timing of the question, roughly two years after the birth, is sufficiently recent to reduce the possibility of recall bias but sufficiently removed to ensure that women are reporting on the full maternity leave. This analysis is based on data from PRAMS-selected women who had live births in 2008 and completed PRAMS-2 in 2010. The weighted response rate for PRAMS-2 is $38.3 \%$. (For more information about PRAMS, see http://www.cdc.gov/prams/.)

\section{Definition of outcome measure}

In the PRAMS-2 survey, mothers were asked four questions about maternity leave. The first question was "Were you employed during any of the last three months of your most recent pregnancy?" The second question was "Did your job offer maternity leave?" The third question (for positive respondents) was "What type of maternity leave did your job offer?" (Response options were: fully-paid maternity leave, partiallypaid maternity leave, and unpaid maternity leave.) The fourth question was "How old was your baby when you first returned to work?" The primary outcome measure in this study is self-reported receipt of fullypaid maternity leave among women who were employed during the last three months of pregnancy. Women who received fully-paid maternity leave have been compared to women who received either partially-paid leave, unpaid leave, or no leave.

\section{Definition of covariates}

The covariates selected and examined were chosen based on prior knowledge of potential confounders, including maternal race/ 
ethnicity, maternal age at birth, maternal education, marital status, and annual household income. Maternal race/ethnicity was taken from the birth certificate. Maternal education, age, marital status, and annual household income were taken from PRAMS-2. For the present analysis, maternal race/ethnicity was classified as: Hispanic, white nonHispanic, black non-Hispanic, American Indian/Alaskan Native nonHispanic or Asian/Pacific Islander non-Hispanic. Annual household income was categorized using Federal Poverty Level (FPL). The federal poverty variable was calculated using annual household income and the number of household dependents from PRAMS-2 questions. We compared women whose annual household income was $<300 \%$ of FPL ( $\$ 61,950$ for a family of four) with women whose annual household income was $>300 \%$ of FPL.

\section{Exclusions and final sample}

We analyzed Oregon PRAMS- 2 data from the 871 respondents with a 2008 live birth. (The PRAMS-2 data were collected in 2010-2011.) As shown in Figure 1, responses from 560 women were excluded from the analysis because they did not work during the last three months of pregnancy or did not answer the question about employment during the last three months of pregnancy leaving 311 respondents. After excluding the 9 respondents who did not answer questions about maternity leave, the final analysis was performed on 302 women.

\section{Statistical techniques}

The SPSS statistical software package version 20 was used to produce univariate measures of the association among selected variables of interest. The Stata statistical software version 13 was used to account for the complex survey design (involving a stratified, weighted sample) for both the bivariate and multivariate modeling.

Descriptive statistics were computed to provide sample size information, and weighted data were used to compute all other analyses. We examined distributions and frequencies of maternity leave types. Bivariate analysis also examined the association between the covariates and receipt of fully-paid maternity leave, compared to conditions of no maternity leave, partially-paid maternity leave, and unpaid maternity leave. Bivariate logistic regression models were constructed to examine the unadjusted odds ratios to determine which maternal characteristics were significantly associated with receiving fully-paid maternity leave. Characteristics that were not significantly associated with receiving fully-paid maternity leave in bivariate logistic analysis were dropped from the final model. Marital status was dropped from the final model because all but one of the women reporting fully-paid maternity leave were married. All numbers reported are unweighted; all percentages reported are weighted unless otherwise noted. The Oregon PRAMS and PRAMS-2 study and informed consent procedures were approved by the Oregon State Public Health/Multnomah County Public Health Institutional Review Board.

\section{Results}

Table 1 shows type of maternity leave among the 302 women who had worked during the last three months of their pregnancies: 54 (17.7\%) were not offered maternity leave; 139 (49.8\%) were offered unpaid maternity leave, $66(16.3 \%)$ were offered partially-paid maternity leave, and 43 (16.1\%) were offered fully-paid maternity leave. Women who had not been offered any maternity leave took longer maternity leave than women who were offered any maternity leave. There was no statistically significant difference in the duration of maternity leave between women who reported receiving unpaid, partially-paid and fully-paid maternity leave.

Table 2 represents the distribution of characteristics of mothers working in the last three months of pregnancy divided into four categories of maternity leave: no maternity leave, unpaid maternity leave, partially-paid maternity leave, and fully-paid maternity leave. The only characteristic that was significantly associated with type of maternity leave was maternal age.

Table 3 shows the results of our multivariate logistic analysis comparing women who reported fully-paid maternity leave to all others (none plus unpaid plus partially-paid maternity leave). We found that, compared to women whose household income was less than $300 \%$ of

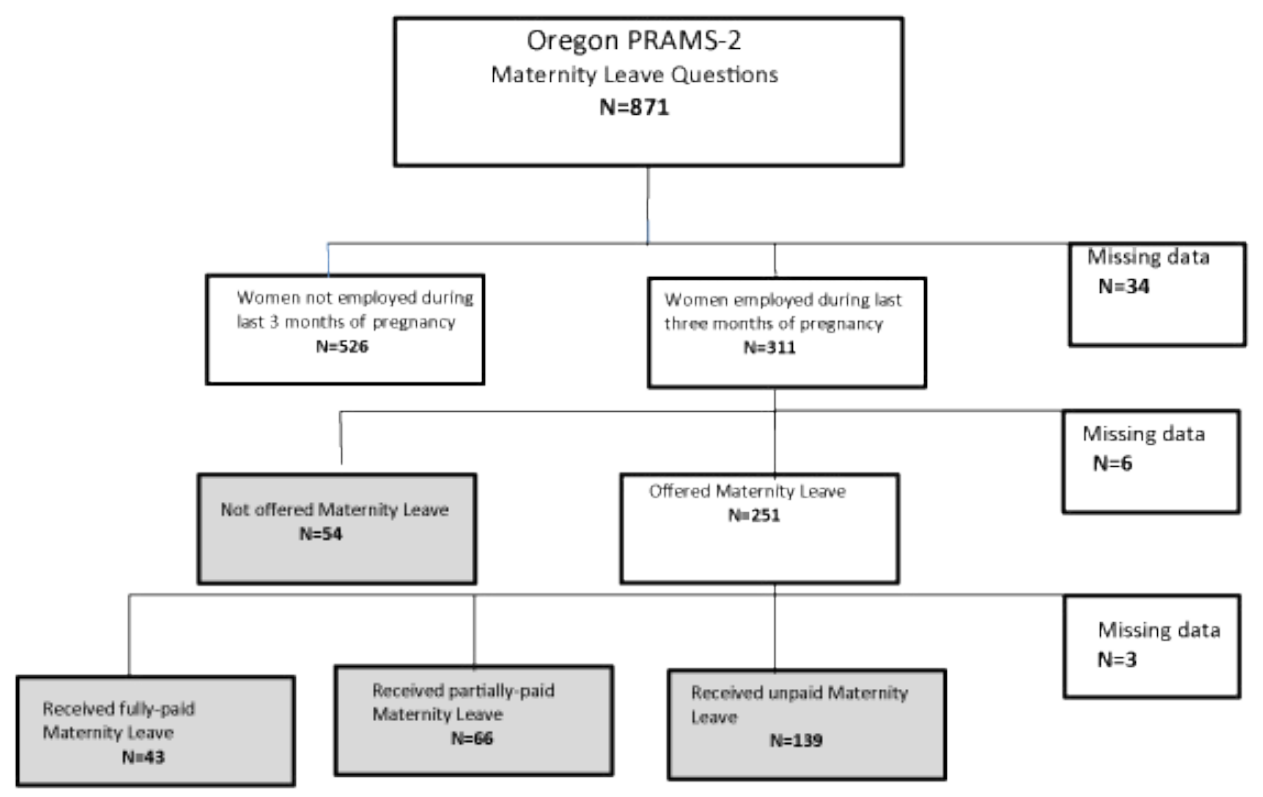

Figure 1: Pattern of responses for analysis, Oregon PRAMS-2, 2008 births 
Table 1: Maternity leave offered to women who had been working during last three months of pregnancy, Oregon PRAMS-2, 2008 births ( $\mathrm{n}=302$ ).

\begin{tabular}{|c|c|c|c|}
\hline Maternity Leave Type & n & Weighted \% & $17.7 \%$ \\
\hline Not offered Maternity Leave & 54 & $49.8 \%$ & 21.75 \\
\hline Offered Unpaid Maternity Leave & 139 & $16.3 \%$ & 12.53 \\
\hline Offered Partially-paid Maternity Leave & 66 & $16.1 \%$ & 13.03 \\
\hline Offered Fully-paid Maternity Leave & 43 & 12.53 \\
\hline
\end{tabular}

Table 2: Characteristics of women who were working during the last three months of pregnancy, Oregon PRAMS-2, 2008 births ( $\mathrm{n}=302$ )

\begin{tabular}{|c|c|c|c|c|c|}
\hline p-value & No & Unpaid & Partially-paid & Fully-paid & Total \\
\hline Maternal Characteristic & $\begin{array}{l}\text { Maternity Leave } \\
\text { n(weighted \%) }\end{array}$ & $\begin{array}{c}\text { Maternity Leave } \\
\text { n(weighted \%) }\end{array}$ & $\begin{array}{l}\text { Maternity Leave } \\
\text { n(weighted \%) }\end{array}$ & $\begin{array}{c}\text { Maternity Leave } \\
\text { n(weighted \%) }\end{array}$ & $\begin{array}{c}\text { Maternity Leave } \\
\text { n(weighted \%) }\end{array}$ \\
\hline Total & 54 & 139 & 66 & 43 & 302 \\
\hline \multicolumn{6}{|c|}{ Annual household income } \\
\hline $\mathrm{FPL}^{3}<300 \%$ & $26(44.8 \%)$ & $75(52.0 \%)$ & $27(41.7 \%)$ & $12(21.6 \%)$ & 140 \\
\hline \multicolumn{6}{|l|}{.076} \\
\hline $\mathrm{FPL}^{3} \geq 300 \%$ & $24(55.2 \%)$ & $60(48.0 \%)$ & $38(58.3 \%)$ & $30(78.4 \%)$ & 152 \\
\hline \multicolumn{6}{|l|}{ Maternal race/ethnicity } \\
\hline Non-Hispanic White & $19(83.3 \%)$ & $50(82.2 \%)$ & $18(71.8 \%)$ & $16(82.0 \%)$ & 103 \\
\hline \multicolumn{6}{|l|}{.228} \\
\hline Hispanic & $4(5.7 \%)$ & $23(11.6 \%)$ & $7(10.8 \%)$ & $7(10.9 \%)$ & 41 \\
\hline Non-Hispanic Asian/PI ${ }^{1}$ & $17(8.1 \%)$ & $25(4.4 \%)$ & $24(12.1 \%)$ & $13(5.7 \%)$ & 79 \\
\hline Non-Hispanic Black & $3(1.0 \%)$ & $18(1.8 \%)$ & $7(3.2 \%)$ & $5(1.0 \%)$ & 33 \\
\hline Non-Hispanic AI/AN ${ }^{2}$ & $9(1.9 \%)$ & $23(2.0 \%)$ & $9(2.0 \%)$ & $2(0.3 \%)$ & 43 \\
\hline \multicolumn{6}{|l|}{ Maternal marital status } \\
\hline Married & $41(80.7 \%)$ & $105(86.8 \%)$ & $51(81.3 \%)$ & $42(98.4 \%)$ & 239 \\
\hline \multicolumn{6}{|l|}{.157} \\
\hline All other & $13(19.3 \%)$ & $34(13.2 \%)$ & $13(18.7 \%)$ & $1(1.6 \%)$ & 61 \\
\hline \multicolumn{6}{|l|}{ Maternal age (years) } \\
\hline$<25$ & $9(9.2 \%)$ & $31(24.0 \%)$ & $10(17.0 \%)$ & $4(8.0 \%)$ & 54 \\
\hline \multicolumn{6}{|l|}{$.0046^{*}$} \\
\hline $26-34$ & $30(38.9 \%)$ & $87(57.9 \%)$ & $37(54.5 \%)$ & $26(77.0 \%)$ & 61 \\
\hline$>35$ & $15(51.9 \%)$ & $21(18.1 \%)$ & $19(28.6 \%)$ & $13(15.0 \%)$ & 61 \\
\hline \multicolumn{6}{|c|}{ Maternal education (years) } \\
\hline$<16$ & $22(36.7 \%)$ & $69(48.9 \%)$ & $20(33.1 \%)$ & $7(26.0 \%)$ & 118 \\
\hline \multicolumn{6}{|l|}{.227} \\
\hline$>16$ & $31(63.3 \%)$ & $70(51.1 \%)$ & $46(66.9 \%)$ & $36(74.0 \%)$ & 183 \\
\hline \multicolumn{6}{|c|}{$\begin{array}{l}\text { n: unweighted number of respondents with characteristic } \\
{ }^{1} \text { Asian/PI: Asian/Pacific Islander } \\
{ }^{2} \mathrm{AI} / \mathrm{AN} \text { : American Indian/Alaska Native } \\
{ }^{3} \mathrm{FPL} \text { : Federal Poverty Level } \\
{ }^{*} \text { Significant at } \mathrm{p}<.05 \text {. }\end{array}$} \\
\hline
\end{tabular}

the FPL, women with household income of greater than or equal to $300 \%$ of FPL were significantly more likely to have been offered fullypaid maternity leave (ORa 3.57; 95\% CI [95\% confidence interval] 1.24-10.27; $\mathrm{p}<0.05)$. We also found that the only statistically significant difference in the likelihood of receiving fully-paid maternity leave by race/ethnicity was that non-Hispanic American Indian/Alaska Native women were significantly less likely than non-Hispanic White women (ORa $0.16 ; 95 \%$ CI $0.03-0.81 ; \mathrm{p}<0.05$ ) to have received fully-paid maternity leave. Maternal marital status was statistically significantly associated with receipt of fully-paid maternity leave in bivariate analysis but was not significant in multivariate analysis. Maternal age and education were not significantly associated in either bivariate or multivariate analysis.

\section{Discussion}

We found that economically well-off women had the greatest access to fully-paid maternity leave. Income trumped most of those characteristics shown in previous studies to matter for access to paid leave including age, education, and, for the most part, race/ethnicity.
By focusing on a geographically homogeneous subset of women Oregon women with 2008 births - our study was able to isolate income as a factor that differentiates women with optimal leave conditions (i.e., fully-paid) from women with less-than-optimal leave conditions. When a woman is deciding whether to take leave to recover from childbirth or bond with her new child, she is weighing myriad factors, key among which is her family's financial well-being. In this calculus, while the difference between "any pay" and "no pay" matters, the difference between "partial pay" and "full pay" may be equally weighty, especially if her wage or salary prior to the child's birth was just enough to make ends meet. Women with low wages or salaries are least likely to be able to save up for an unpaid or partially-paid leave.

More research about patterns and correlates of the characteristics of women who receive various levels of wage replacement during maternity leave can help inform evidence-based health care guidelines as well as public policy and legislation. Access to job-protected, wagereplaced maternity leave can build economic security and promote women's health and family well-being. 
Table 3: Characteristics of women who worked during last three months of pregnancy and received fully-paid maternity leave, Oregon PRAMS-2 ( $\mathrm{n}=302$ )

\begin{tabular}{|c|c|c|c|c|c|}
\hline Maternal Characteristic & $\begin{array}{c}\text { Fully-paid } \\
\text { Maternity Leave }\end{array}$ & n (unweighted) & $\%$ (weighted) & $\begin{array}{c}\text { Bivariate odds ratio } \\
(95 \% \mathrm{CI})\end{array}$ & $\begin{array}{c}\text { Multivariate odds ratio } \\
(95 \% \text { CI) }\end{array}$ \\
\hline Total & 43 & 302 & $16.1 \%$ & & \\
\hline \multicolumn{6}{|l|}{ Annual household income } \\
\hline $\mathrm{FPL}^{3}<300 \%$ & 12 & 140 & $8.1 \%$ & Referent & Referent \\
\hline $\mathrm{FPL}^{3} \geq 300 \%$ & 30 & 152 & $23.1 \%$ & $3.42(1.24-9.45)^{*}$ & $3.57(1.24-10.3)^{*}$ \\
\hline \multicolumn{6}{|l|}{ Maternal race/ethnicity } \\
\hline Non-Hispanic White & 16 & 103 & $16.6 \%$ & Referent & Referent \\
\hline Hispanic & 7 & 41 & $17.1 \%$ & $1.03(0.38-2.80)$ & $1.37(0.44-4.24)$ \\
\hline Non-Hispanic Asian/PI ${ }^{1}$ & 13 & 79 & $14.2 \%$ & $0.83(0.36-1.90)$ & $0.83(0.36-1.92)$ \\
\hline Non-Hispanic Black & 5 & 33 & $9.3 \%$ & $0.51(0.16-1.59)$ & $0.84(0.25-2.80)$ \\
\hline Non-Hispanic AI/AN² & 2 & 43 & $3.1 \%$ & $0.16(0.03-0.77)^{*}$ & $0.16(0.03-0.81)^{*}$ \\
\hline \multicolumn{6}{|l|}{ Maternal marital status } \\
\hline Married & 42 & 239 & $18.4 \%$ & $11.6(1.46-92.4)^{*}$ & \\
\hline All other & 1 & 61 & $1.9 \%$ & Referent & \\
\hline \multicolumn{6}{|l|}{ Maternal age (years) } \\
\hline$<25$ & 4 & 54 & $7.3 \%$ & Referent & \\
\hline $26-34$ & 26 & 180 & $21.7 \%$ & $3.54(0.82-15.2)$ & \\
\hline$>35$ & 13 & 68 & $9.5 \%$ & $1.34(0.26-7.00)$ & \\
\hline \multicolumn{6}{|l|}{ Maternal education (years) } \\
\hline$<16$ & 7 & 118 & $10.3 \%$ & Referent & \\
\hline$>16$ & 36 & 183 & $20.0 \%$ & $2.17(0.70-6.72)$ & \\
\hline
\end{tabular}

n: unweighted number of respondents with

characteristic

$*: \mathrm{p}<0.05$

${ }^{1}$ Asian/PI: Asian/Pacific Islander

${ }^{2} \mathrm{AI} / \mathrm{AN}$ : American Indian/Alaska Native

${ }^{3}$ Federal Poverty Level

\section{What does this work contribute?}

Most of the literature on maternity leave compares paid maternity leave to no maternity leave. We have been able to increase the granularity of this analysis by looking at four distinct types of maternity leave: fullypaid, partially-paid, unpaid and none. We have focused most of our analysis on the comparison between fully-paid maternity leave and the other three types.

\section{Limitations}

This work has several limitations. First, we believe that some women used vacation and sick leave and interpreted this as maternity leave. This would lead us to overestimate the proportion of women who were offered fully-paid maternity leave. Second, we do not know which Oregon employers offer fully-paid maternity leave. For instance, the programmatic implications would be different if we knew that most of the fully-paid maternity leave was being offered by school systems than if it was mostly being offered by a few large corporate employers. This knowledge would influence the targeting of awareness and outreach campaigns and identify which workers (for instance, public sector versus private sector) might have the most to gain from legislative efforts. Third, report of maternity leave is based on mother's self report and may be subject to recall bias two years after the birth. Fourth, although PRAMS and PRAMS-2 are population-based, the sample size and the response rate (although weighted) are modest and may limit the generalizability of our findings to the entire population of birthing women in Oregon.

\section{Directions for Future Research}

Because we do not know which Oregon employers offer fully-paid maternity leave, future research should focus on surveying employers to learn about business' maternity leave policies. This may help shape future initiatives to increase maternity leave.

\section{Implications for Practice and/or Policy}

We found that most women do not get any paid maternity leave and that less than $20 \%$ of working women get fully-paid maternity leave. We found that higher-income women are far more likely to get fully-paid maternity leave than lower-income women. Combined with existing evidence on the benefits of maternity leave, policies ensuring fully-paid maternity leave will be particularly beneficial to lower-income women.

The results of this first state population-based study of the association between high income and fully-paid maternity leave have implications for future research and policy. Currently, the United States is the only high-income nation that does not offer paid maternity leave as part of federal policy. Further, rather than seeing an expansion in paid leave, for some segments of the population we see leave being curtailed. For instance, access to paid maternity leave at large companies is decreasing; the percentage of larger employers voluntarily offering fully-paid maternity leave for new mothers fell from 17\% in 2005 to $9 \%$ in 2012 [25].

The lives of working families and the economy could be improved if the United States adopted a national paid leave policy. A study on labor market policies revealed that providing an average amount of paid maternity leave (15 weeks) in the United States, is likely to have a significant positive impact on productivity growth [26]. Another study conducted in California, where there is a state-level paid leave policy, showed a marked level of small business and employer support for paid family leave several years after implementation [27]. There is some evidence that paid maternity leave disproportionately helps the poor [28,29].

One direction for policy changes is for cities and states to enact laws requiring paid maternity leave and/or sick leave. Five states - California, Hawaii, New Jersey, New York, and Rhode Island - currently have in 
place disability insurance programs that allow women to use "shortterm" or "temporary" disability insurance to cover a portion of lost wages for leave during pregnancy and immediately after giving birth. California and New Jersey have also enacted legislation to provide an additional 6 weeks of paid family leave for bonding with a newborn or newly adopted child. In 2013, the Portland (Oregon) City Council, in 2013, passed an ordinance mandating earned sick leave for all employees working in the city. Under the measure, employers doing business in the city must allow their employees to earn sick time (one hour for every 30 hours worked). This took effect in January 2014. Employees may use this accrued leave when they or a family member are sick, injured, or need preventive health care [28].

Our study contributes to existing work by demonstrating that disparities in access exist not just for any type of paid leave but specifically for fully-paid maternity leave. Further, those segments of the population-lower-income women-who could be aided most by access to fully-paid maternity leave are significantly less likely to have access to it. A national, universal paid leave policy would ameliorate such disparities and encourage the well-being of women and families.

\section{Authorship}

Jena L. Fellenzer, MPH, did this work as a Council of State and Territorial Epidemiologists (CSTE) Applied Epidemiology Fellow at the Oregon Public Health Division. She is interested in maternal depression, inequalities in birth outcomes, and maternal and child health community outreach and education.

Kenneth D. Rosenberg, MD, MPH, is Affiliate Assistant Professor at Oregon Health \& Science University-Portland State University School of Public Health. He was the maternal and child health epidemiologist for the Oregon Public Health Division and the Project Director of the Oregon PRAMS survey and has published on breastfeeding, SIDS, immunizations, and child health surveillance.

Danielle J. Lindemann, $\mathrm{PhD}$, is Assistant Professor of Sociology at Lehigh University. Her research interests include gender, sexuality, culture, and work.

Linda Houser, $\mathrm{PhD}$, is an Assistant Professor and $\mathrm{PhD}$ Program Director at Widener University's Center for Social Work Education. Her focus is on financial, workplace, and caregiving security for women and families.

Alfredo P. Sandoval, MS, MBA, is a Research Analyst in the Maternal and Child Health Assessment and Evaluation Unit of the Oregon Public Health Division. His focus is on the statistical issues of collecting and analyzing Oregon PRAMS data.

Kathryn L. Broderick, MPA, was the manager of the Maternal and Child Health Assessment and Evaluation Unit of the Oregon Public Health Division. Her focus is on $\mathrm{MCH}$ data for policy-making and program development, especially regarding health equity.

\section{Funding Statement}

This study was supported by Ms. Fellenzer's Applied Epidemiology Fellowship Program administered by the Council of State and Territorial Epidemiologists (CSTE) and funded by the Centers for Disease Control and Prevention (CDC) Cooperative Agreement Number 1U380T000143-01.

\section{Acknowledgments}

The authors would like to thank Alfredo P. Sandoval, Tina Kent, Caitlyn Howell, and Karen White for their assistance, as well as Dana Britton and the Center for Women and Work at Rutgers University.

\section{References}

1. Han W, Ruhm C, Waldfogel J (2007) Parental Leave Policies and Parents' Employment and Leave-Taking. J Policy Anal Manage 28: 29-54. [Crossref]

2. Berger L, Hill J, Waldfogel J (2005) Maternity Leave, Early Maternal Employment and Child Health and Development in the US. The Economic Journal 115: 29-47.

3. Zigler E, Muenchow S, Ruhm C (2012) Time off with baby: The case for paid care leave. Washington, DC: Zero to Three. [Crossref]

4. Chatterii P, Markowitz S (2005) Does the Length of Maternity Leave Affect Maternal Health? Southern Economic Journal 72: 16-41.

5. Clark R, Shibley Hyde J, Essex M, Klein M (1997) Length of Maternity Leave and Quality of Mother-Infant Interactions. Child Development 68: 364-383.

6. Ruhm C (2000) Parental Leave and Child Health. J Health Econ 19: 931-960.

7. Heymann J, Raub A, Earle A (2011) Creating and Using New Data Sources to Analyze the Relationship Between Social Policy and Global Health: The Case of Maternal Leave. Public Health Rep 26: 127-134. [Crossref]

8. Houser L, Vartanian T (2012b) Policy Matters: Public Policy, Paid Leave for New Parents, and Economic Security for U.S. Workers.

9. Waldfogel J (1999) The Impact of the Family and Medical Leave Act. J Policy Anal Manage 18: 281-302.

10. Baxter J (2008) Timing of mothers' return to work after childbearing: Variations by job characteristics and leave use. Melbourne, Victoria: Australian Institute of Family Studies.

11. Rossin-Slater M, Ruhm C, Waldfogel J (2013) The Effects of California's Paid Family Leave Program on Mothers' Leave-Taking and Subsequent Labor Market Outcomes. $J$ Policy Anal Manage 32: 224-245. [Crossref]

12. Houser L, Vartanian T (2012a) Pay Matters: The Positive Economic Impact of Paid Family Leave for Families. Businesses and the Public.

13. Boushey H (2008) Family Friendly Policies: Helping Mothers Make Ends Meet. Review of Social Economy 66: 51-70.

14. Guendelman S, Goodman J, Kharrazi M, Lahiff M (2014) Work-family balance after childbirth: the association between employer-offered leave characteristics and maternity leave duration. Matern Child Health J 18: 200-208. [Crossref]

15. Laughlin L (2011) Maternity leave and employment patterns of first-time mothers 1961-2008. U.S. Census Bureau.

16. Klerman J, Daley K, Pozniak A (2012) Family and Medical Leave in 2012: Technical Report.

17. United States Department of Labor (2012) Family and Medical Leave in 2012.

18. Ross Phillips K (2004) Getting time off: Access to leave among working parents.

19. Waldfogel J (2001) Family and Medical Leave; Evidence From 2000 Surveys. Monthly Labor Review 124: 17-23.

20. Ross Phillips K (2002) Working for All Families? Family Leave Policies in the United States. In Kimmel, J. \& Hoffman, E. (Eds.), The Economics of Work and Family (pp. 159-180). Kalamazoo, MI: W.E. Upjohn Institute for Employment Research.

21. Hegewisch A, Hara Y (2013) Maternity, Paternity, and Adoption Leave in the United States.

22. National Partnership for Women and Families (2014) Expecting Better: A State-byState Analysis of Laws That Help New Parents.

23. Shepherd-Banigan M, Bell J (2014) Paid Leave Benefits Among a National Sample of Working Mothers with Infants in the United States. Matern Child Health J 18: 286-295. [Crossref]

24. Women's Health USA (2011) United States Department of Health and Human Services. 25. Matos K, Galinsky E (2012) 2012 National Study of Employers.

26. Bassanini A, Venn D (2008) The Impact of Labour Market Policies on Productivity in OECD Countries, International Productivity Monitor. Centre for the Study of Living Standards 17: 3-15. 
Fellenzer JL (2018) Who gets fully-paid maternity leave? population-based survey of postpartum women, oregon, 2010

27. Appelbaum E, Milkman R (2011) Leaves that pay: employer and worker experiences with paid family leave in California. Center for Economic and Policy Research Publication.

28. The City of Portland, Oregon (2014) Portland Protected Sick Time Ordinance.
29. Guendelman S, Pearl M, Graham S, Angulo V, Kharrazi M (2006) Utilization of Pay-in Antenatal Leave Among Working Women in Southern California. Matern Child Health $J$ 10: 63-73.

Copyright: (C2018 Fellenzer JL. This is an open-access article distributed under the terms of the Creative Commons Attribution License, which permits unrestricted use, distribution, and reproduction in any medium, provided the original author and source are credited. 